Editorial

\title{
Welcome to Fermentation: A New Multidisciplinary Open Access Journal
}

\author{
Badal C. Saha \\ Bioenergy Research Unit, National Center for Agricultural Utilization Research, United States \\ Department of Agriculture, Agricultural Research Service (USDA-ARS), Peoria, IL 61604, USA; \\ E-Mail: Badal.Saha@ars.usda.gov
}

Received: 17 December 2014 / Accepted: 18 December 2014 / Published: 24 December 2014

It is my great pleasure to welcome you to a new open access journal, Fermentation, which represents a multidisciplinary scope that meets the growing need for a high quality peer-reviewed international journal with easy access to all researchers globally. The journal aims at a broad multidisciplinary readership, which includes both academia and industries, and covers broad areas of research, development and technological advances in all aspects of fermentation. Fully comprehensive in its scope, the journal coverage includes without being limited to:

- Fermentation process and product development

- Strain improvement

- Bioprocess and metabolic engineering

- Scale up of fermentation processes

- Downstream processing of fermentation products

- Microbial physiology and metabolism

- Applied genetics and molecular biotechnology

- Genomics, proteomics, metabolomics and systems biology

- Bioinformatics

- Bioreactor design, monitoring, biosensors and instrumentation

- Biosafety and biosecurity

The importance of developing new fermentation processes and products for a variety of food, pharmaceutical, commodity and platform chemicals is fast growing. Fermentation will serve as an active platform for publishing the high quality research in the field. It will publish original research papers, review articles, short communications and technical notes on all areas of fermentation related to new and emerging products, processes and technologies. We aim to encourage researchers to publish their 
experimental, theoretical and computational results in as much detail as necessary. We thus restrict neither paper length nor number of figures and tables.

We hope that you will share our enthusiasm for this new journal and look forward to working with you to make Fermentation a leader in its field. A superb and diverse editorial board and invited well qualified reviewers will assure high scientific standards. Publication in Fermentation guarantees instantaneous free access to the article via internet. Your contributions are vital for the success of this new journal from MDPI. The publication fees are fully waived for papers submitted in 2015 and 2016. Proposals for editing a special issue of the journal for a particular topical area are always welcome.

(C) 2014 by the authors; licensee MDPI, Basel, Switzerland. This article is an open access article distributed under the terms and conditions of the Creative Commons Attribution license (http://creativecommons.org/licenses/by/4.0/). 